\title{
Involvement of ZEB1 and Snail1 in excessive production of extracellular matrix in Fuchs endothelial corneal dystrophy
}

\author{
Naoki Okumura1,2, Ryuki Minamiyama', Leona TY Ho' ${ }^{1}$ EunDuck P Kay ${ }^{1}$, Satoshi Kawasaki², Theofilos Tourtas ${ }^{3}$, \\ Ursula Schlötzer-Schrehardt ${ }^{3}$, Friedrich E Kruse ${ }^{3}$, Robert D Young ${ }^{4}$, Andrew J Quantock ${ }^{4}$, Shigeru Kinoshita ${ }^{2}$ and \\ Noriko Koizumi ${ }^{1}$
}

Fuchs endothelial corneal dystrophy (FECD) due to corneal endothelial cell degeneration is a major cause of corneal transplantation. It is characterized by abnormal deposition of extracellular matrix (ECM), such as corneal guttae, accompanied by a loss of endothelial cells. Although recent studies have revealed several genomic factors, the molecular pathophysiology of FECD has not yet been revealed. In this study, we establish a cellular in vitro model by using immortalized corneal endothelial cells obtained from late-onset FECD and control patients and examined the involvement of epithelial mesenchymal transition (EMT) on excessive ECM production. We demonstrate that the EMT-inducing genes ZEB1 and SNAI1 were highly expressed in corneal endothelial cells in FECD and were involved in excessive production of ECM proteins, such as type I collagen and fibronectin through the transforming growth factor (TGF)- $\beta$ signaling pathway. Furthermore, we found that SB431542, a specific inhibitor of TGF- $\beta$ type I ALK receptors, suppressed the expression of ZEB1 and Snail 1 followed by reduced production of ECM. These findings suggest that increased expression levels of ZEB1 and Snail1 in FECD cells were responsible for an increased responsiveness to TGF- $\beta$ present in the aqueous humor and excessive production of ECM. In addition, these results suggest that the regulation of EMT-related genes by blocking the TGF- $\beta$ signaling pathway may be a feasible therapeutic strategy for FECD.

Laboratory Investigation (2015) 95, 1291-1304; doi:10.1038/labinvest.2015.111; published online 24 August 2015

Fuchs endothelial corneal dystrophy (FECD) is a degenerative disease of the corneal endothelium. The phenotypic clinical features of FECD are characterized by the presence/formation of corneal guttae, which are collagenous excrescences of the corneal endothelial basement membrane (Descemet's membrane). ${ }^{1}$ As the disease progresses, an increasing density of guttae and an aberrant thickening of Descemet's membrane becomes evident; this is caused by the abnormal/excessive accumulation of extracellular matrix (ECM). This accumulation of ECM is accompanied by a gradual loss of corneal endothelial cells (CECs), thereby leading to a functional impairment of the endothelium to pump excess fluid out of the corneal stroma. ${ }^{2}$ This eventually results in corneal edema and ultimately in vision loss and pain. Currently, corneal transplantation using post-mortem donor tissue is the only therapeutic choice for the treatment of FECD. ${ }^{3}$ In the United States, FECD affects as much as $5 \%$ of the population aged over $40 .^{4}$ Visual disturbance due to FECD is the most common indication for corneal transplantation in the US. ${ }^{5}$

There are two forms of FECD that are defined by the age of onset, the less common early-onset FECD, and the classic late-onset FECD. Genetic linkage and association studies revealed that early-onset FECD exhibits linkage to chromosome 1q and that late-onset FECD has been linked to chromosomes 13 (FCD1), 18 (FCD2), 5 (FCD3), and 9 (FCD4). Late-onset classic FECD can either be familial or sporadic, with an onset typically occurring after the age of 40 years. Although mutations in the zinc-finger E-box binding homeobox 1 (ZEB1) gene ${ }^{6,7}$ and the solute carrier family 4 member 11 (SLC4A11) gene ${ }^{8,9}$ have been reported as causative of late-onset

${ }^{1}$ Department of Biomedical Engineering, Faculty of Life and Medical Sciences, Doshisha University, Kyotanabe, Japan; ${ }^{2}$ Department of Ophthalmology, Kyoto Prefectura University of Medicine, Kyoto, Japan; ${ }^{3}$ Department of Ophthalmology, University of Erlangen-Nürnberg, Erlangen, Germany and ${ }^{4}$ Structural Biophysics Group, School of Optometry and Vision Sciences, Cardiff University, Cardiff, UK

Correspondence: Professor N Koizumi, MD, PhD, Department of Biomedical Engineering, Faculty of Life and Medical Sciences, Doshisha University, Kyotanabe 610-0321, Japan.

E-mail: nkoizumi@mail.doshisha.ac.jp

Received 5 December 2014; revised 30 May 2015; accepted 30 June 2015 
FECD, these mutations were only rarely observed in the patient population. On the other hand, Baratz et al ${ }^{10}$ reported that a genome-wide association study (GWAS) revealed a highly significant association between single nucleotide polymorphisms in transcription factor 4 genes (TCF4) in classic late-onset FECD. In addition, involvement of EMT in FECD was hypothesized, as the E-protein family (E2-2) -which is coded by TCF4 - has a role in EMT. Contrary to the increased genetic evidence of FECD, little is known about the molecular pathogenesis of gradual CEC damage in association with excessive accumulation of ECM.

In this study, we investigated the molecular mechanisms of excessive ECM production as a possible cause of ER stress ${ }^{11}$ in CECs in FECD. For this purpose, we established an FECD cellular in vitro model using immortalized cell lines derived from FECD and control patients. Since the involvement of EMT in FECD is hypothesized from GWAS analysis, ${ }^{10}$ EMTinducing genes and their effect on excessive production of ECM were investigated. In addition, we assessed the involvement of the transforming growth factor (TGF)- $\beta$ signaling pathway in the expression of EMT-related genes and ECM production. Finally, we tested the inhibition of TGF- $\beta$ signaling to suppress excessive ECM production and its feasibility as a possible therapeutic target for treating FECD.

\section{MATERIALS AND METHODS Materials}

Dulbecco's modified Eagle's medium was purchased from Nacalai Tesque (Kyoto, Japan). FNC Coating Mix was purchased from Athena Environmental Sciences (Baltimore, MD). Collagenase A was purchased from Roche Applied Science (Penzberg, Germany). Epidermal growth factor, ascorbic acid, calcium chloride, collagen type I antibody, and propidium iodide were purchased from Sigma-Aldrich (St Louis, MO). DAPI was purchased from Vector Laboratories (Burlingame, CA), and fibronectin antibody was purchased from BD Biosciences (San Jose, CA, USA), Further, $\mathrm{Na}^{+} / \mathrm{K}^{+}$-ATPase antibody was purchased from Upstate Biotec (Lake Placid, NY), ZO-1 antibody was purchased from Zymed Laboratories (South San Francisco, CA), collagen type IV antibody was purchased from Abcam (Cambridge, UK), and collagen type ( $\alpha 2)$ VIII antibody was purchased from Abgent (San Diego, CA). The primary antibodies of ZEB1 and Snaill were purchased from Cell Signaling Technology (Danvers, MA, USA). TGF $\beta 1$, TGF $\beta 2$, and TGF $\beta$ neutralizing antibodies were purchased from R\&D Systems (Minneapolis, MN). SB431542 was purchased from Tocris Bioscience (Bristol, UK). Further, Smad3 inhibitor was purchased from Merck Millipore (Billerica, MA). FGF-2, Trypsin-ethylenediaminetetraacetic acid (EDTA), OptiMEM-I, Alexa Fluor 488-conjugated goat anti-mouse IgG, Alexa Fluor 488-conjugated Donkey anti-rabbit IgG, Alexa Fluor 594-conjugated donkey anti-mouse IgG, Alexa Fluor 594-conjugated Donkey anti-rabbit IgG, Snaill Stealth RNAi ((SNAI_1; HSS143995, SNAI_2; HSS143996, SNAI_3; HSS143997), ZEB1 Stealth RNAi ((ZEB1_1; HSS110548,
ZEB_2; HSS110549. ZEB1_3; HSS186235), Stealth RNAi negative control low GC $\sharp 2$, Lipofectamine RNAiMAX, lentiviral vector (pLenti6.3_V5-TOPO), and helper plasmids (pLP1, pLP2, and pLP/VSVG) were purchased from Life Technologies (Carlsbad, CA). Transfection reagent was purchased from (Fugene HD; Promega, Madison, WI). RNeasy mini kit was purchased from Qiagen (Hilden, Germany). ReverTra Ace was purchased from Toyobo (Osaka, Japan).

\section{Ethics Statement}

The human tissue used in this study was handled under the guidelines based on the ethical principles of the Declaration of Helsinki. Written informed consent was acquired from FECD patients, corneal buttons were obtained during the procedure of penetrating keratoplasty, and stripped Descemet's membranes with CECs were obtained during Descemet's membrane endothelial keratoplasty (DMEK). Normal human donor corneas were obtained from SightLife, Seattle, WA (http://www.sightlife.org/).

\section{Immortalization of CECs}

Descemet's membranes, including the CECs, were stripped from three normal human donor corneas and from corneas of three FECD patients during DMEK, and were cultured according to modified published protocols. ${ }^{12,13}$ After culturing for 14 days, the FECD-derived CECs and the control CECs were immortalized using SV40 and hTERT to produce iFECD and iHCEC cell lines, respectively. The coding sequences of the SV40 large T antigen and hTERT genes were amplified by PCR and were TA-cloned into a commercial lentiviral vector. Thereafter, the lentiviral vectors were transfected to human embryonic kidney 293 T cells (RCB2202; Riken Bioresource Center, Ibaraki, Japan) along with three helper plasmids (pLP1, pLP2, and pLP/VSVG) using a transfection reagent. After $48 \mathrm{~h}$ of transfection, the supernatant of the culture medium was harvested. For lentiviral transduction, the viruscontaining supernatants of both genes were added to the cultures of HCECs in the presence of $5 \mu \mathrm{g} / \mathrm{ml}$ of polybrene.

\section{Cell Culture}

The immortalized cells were cultured in Dulbecco's Modified Eagle's Medium (DMEM) containing 10\% FBS and 1\% penicillin and streptomycin. Once the immortalized cells were $80 \%$ confluent, the cells were trypsinized with $0.05 \%$ TrypsinEDTA and passaged. For general usage, prior to seeding the cells, the culturing plates were coated with FNC-coating mix. However, for the analysis of ECM production, the culturing plates were uncoated. To test the effect of TGF $\beta$ on immortalized cells, the cells were grown to $60-70 \%$ confluence and starved in a serum-free medium for $24 \mathrm{~h}$. A supplement of $\operatorname{TGF} \beta 1(1,3$, and $10 \mathrm{ng} / \mathrm{ml})$ or $\operatorname{TGF} \beta 2$ $(10 \mathrm{ng} / \mathrm{ml})$ was added to the serum-free media for $24 \mathrm{~h}$ of incubation. For inhibition of the TGF $\beta$ signaling pathway, cells were supplemented with $\operatorname{SB} 431542(1,3$, and $10 \mu \mathrm{M})$, 

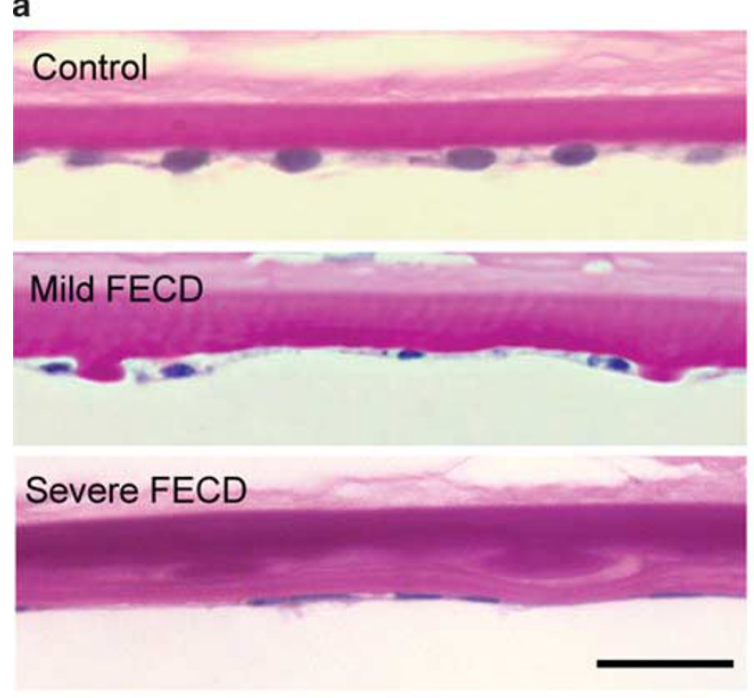

b
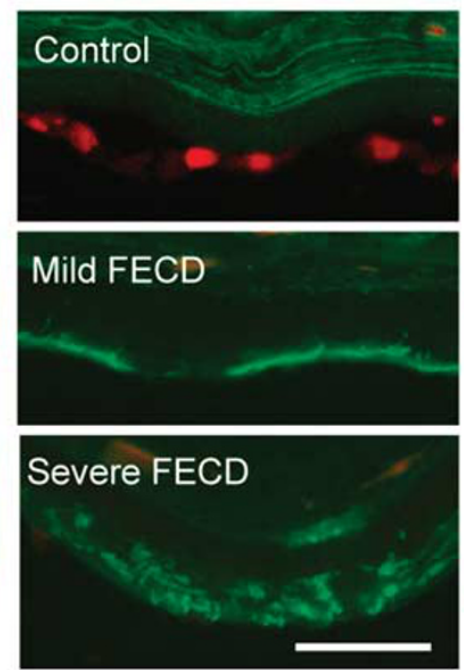

c
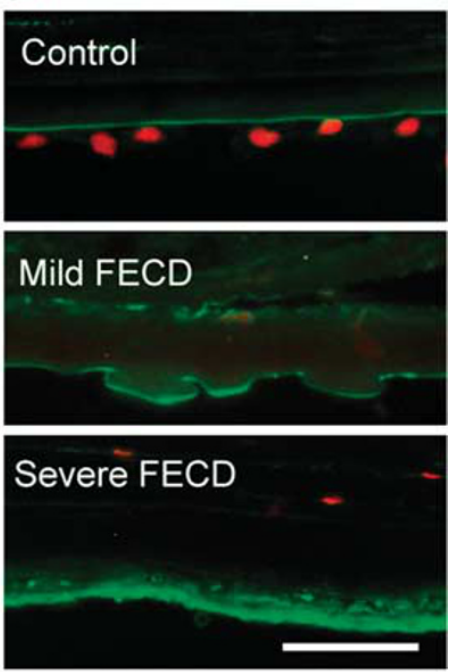
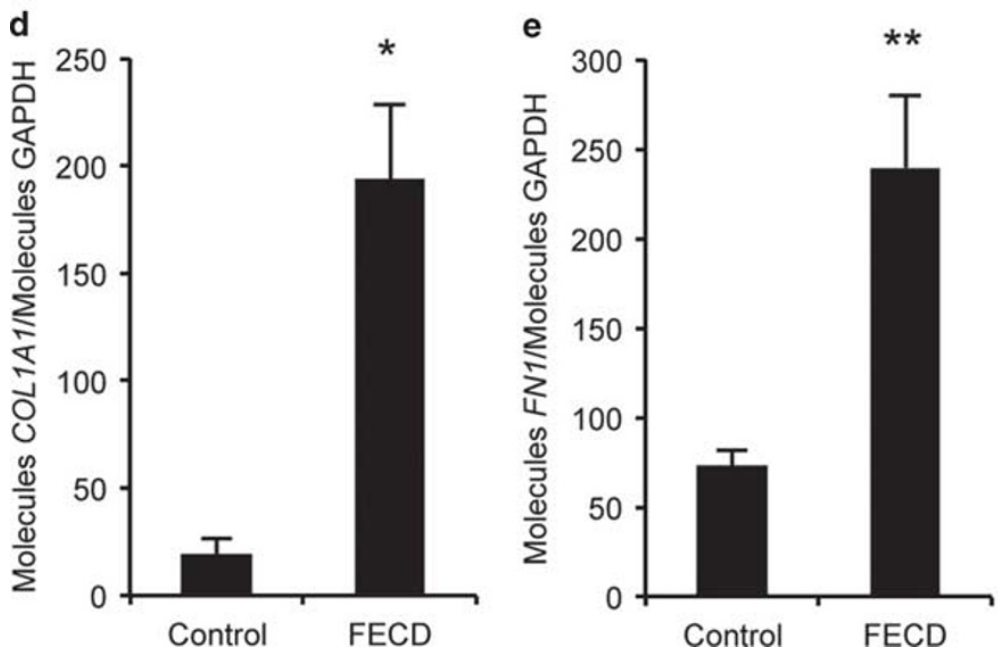

Figure 1 Expression levels of extracellular matrix (ECM) in CECs and Descemet's membrane of FECD patients. (a) Representative PAS staining images of healthy donor cornea and FECD patient cornea. Scale bar, $50 \mu \mathrm{m}$. (b and c) Expression of collagen type I (b) and fibronectin (c) in healthy donor cornea and FECD patient cornea was assessed using immunofluorescence staining. Nuclei were stained by propidium lodide. Scale bar, $50 \mu \mathrm{m}$. (d and $\mathbf{e}$ ) Quantitative determination of mRNA levels of COL1A1 (d) and FN1 (e) in corneal endothelial specimens from donor cornea and patients with Fuchs corneal dystrophy using real-time PCR. Data were normalized to GAPDH and are expressed as molecules of interest per molecules GAPDH. ${ }^{*} P<0.01$, ** $<<0.05$. CECs, corneal endothelial cells; FECD, Fuchs endothelial corneal dystrophy; GAPDH, glyceraldehyde-3-phosphate dehydrogenase; PAS, periodic acid-Schiff.

Smad3 inhibitor $(3 \mu \mathrm{M})$, or TGF $\beta 1$-neutralizing antibody $(500 \mathrm{ng} / \mathrm{ml})$ in serum-free medium and incubated for $24 \mathrm{~h}$.

\section{Knockdown of Genes by siRNA}

The immortalized cells were seeded at a density of $2 \times 10^{4}$ cells/ $\mathrm{cm}^{2}$ into a 24-well plate and incubated with RNAi duplex (ZEB1: ZEB1_1, ZEB1_2, and ZEB1_3; Snail1: SNAI_1, SNAI1_2, and SNAI1_3) and Lipofectamine RNAiMAX according to the manufacturer's protocol. Random RNAi low GC was used as a control and quantitative real-time PCR was performed to assess the knockdown of the ZEB1 or Snaill genes.

\section{ECM Production Assay}

To evaluate the ECM deposition, $1 \times 10^{5}$ cells were seeded onto Corning Transwell polyester membrane cell culture inserts and grown until confluence. The entire Transwell inserts were fixed with $2.5 \%$ glutaraldehyde and $2 \%$ paraformaldehyde in $0.1 \mathrm{M}$ Sorensen phosphate buffer. The membranes were embedded into either OCT compound or prepared for transmission electron microscopy analysis. Cryosectioned specimens were used for hematoxylin-eosin (HE) staining and immunofluorescence staining analysis.

\section{Periodic Acid-Schiff (PAS) Staining and Immunocytochemistry}

Cryosectioned corneas were fixed with 4\% paraformaldehyde and stained with PAS for inspection at the light microscope level. For immunocytochemistry, cryosectioned specimens or CECs cultured on glass slides were fixed with $4 \%$ 
a

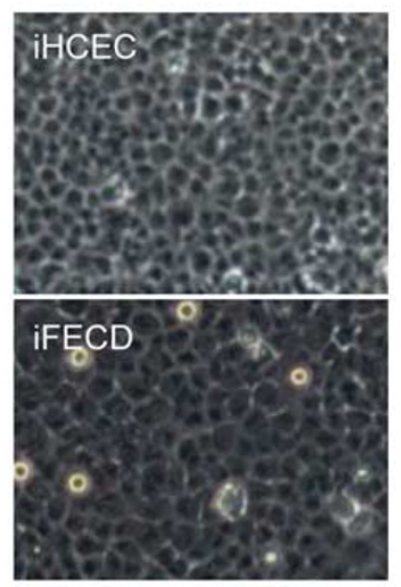

b

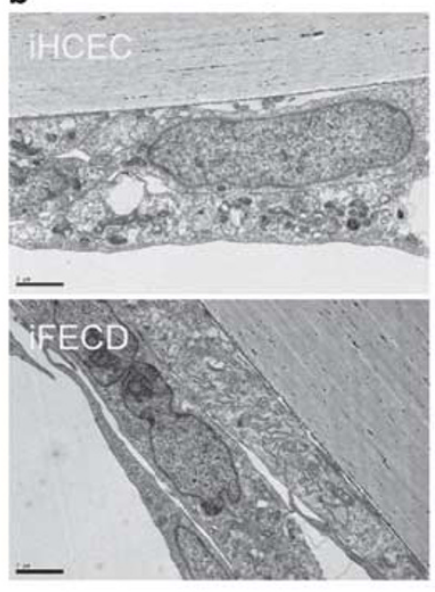

C $\mathrm{Na}^{+} / \mathrm{K}^{+}-\mathrm{ATPase}$
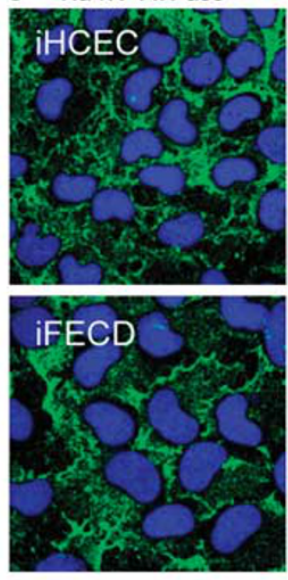
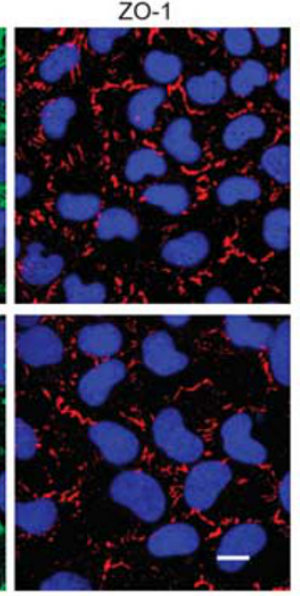

d

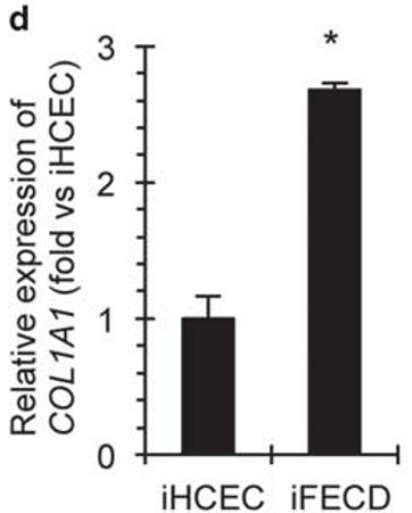

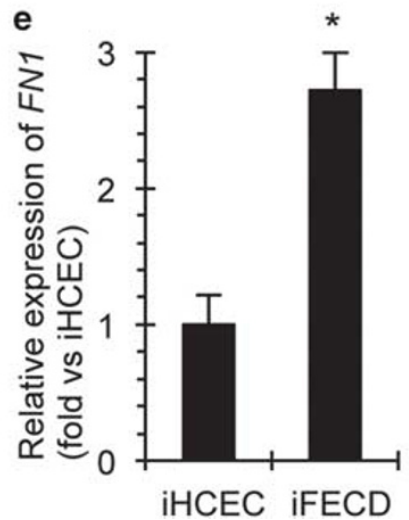

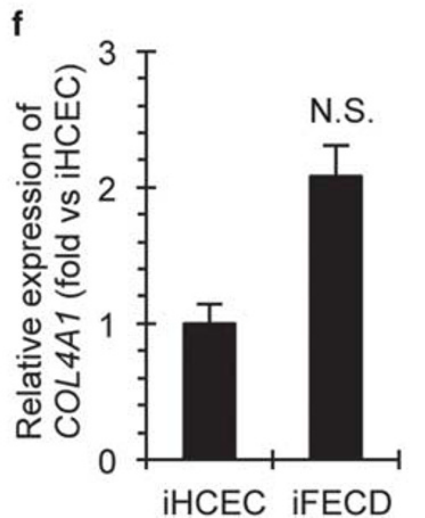

g

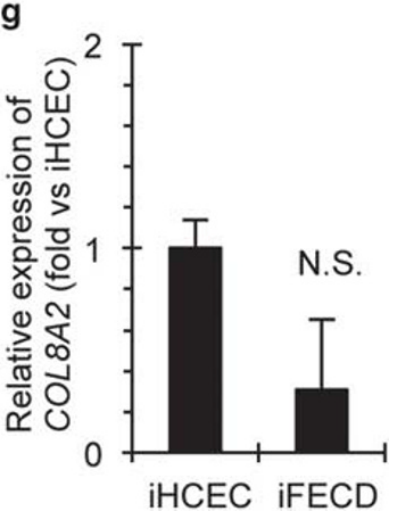

Figure 2 Excessive production of extracellular matrix (ECM) by iFECD. (a) Representative phase contrast images of immortalized HCEC established from three individual donor corneas (iHCEC) and immortalized HCEC established from three individual FECD patients (iFECD). Scale bar $=100 \mu$ m. (b) Ultra structural analysis of both iHCEC and iFECD cultured on Corning Transwell polyester membrane cell culture inserts was observed using TEM. Scale bar $=2 \mu \mathrm{m}$. (c) Function related markers of CECs ( $\mathrm{Na}^{+} / \mathrm{K}^{+}$-ATPase and ZO-1) were immunostained in iHCEC and iFECD. Nuclei was stained by DAPI. Scale bar $=100 \mu \mathrm{m}$. (d-g) Real-time PCR was performed to analyze the expression levels of pathologic ECMs of Descemet's membrane (COL1A1 and FN1) and Descemet's membrane component ECMs (COL4A1 and COL8A2) both in iHCEC and iFECD. Triplicate experiments were performed in three independent iHCEC and iFECD. Representative data were shown both in iHCEC and iFECD batches. ${ }^{*} P<0.01$. (h-k) iHCEC and iFECD were cultured, and the expression of collagen type I, fibronectin, and collagen types IV and VIII were assessed using immunofluorescence staining. The pictures depict three independent experiments. Scale bar $=100 \mu \mathrm{m}$. (I) ECM was morphologically analyzed by transmission electron microscopy (TEM) in iHCEC and iFECD cultured on a Corning Transwell polyester membrane cell culture insert. The representative TEM image shows that iHCEC cells maintained the normal ultra-structure morphology (i), iFECD cells exhibited indications of intracellular ECM production (ii), fibrillar ECM between cells (iii), and extracellular ECM (iv). Asterisk indicates ECM. Scale bar $=\mathbf{a}$ and $\mathbf{b}, 1 \mu \mathrm{m} ; \mathbf{c}, 100 \mathrm{~nm}$; and $\mathbf{d}, 200 \mathrm{~nm}$. The pictures are representative of iHCEC and iFECD established from three independent donors and patients, respectively. ( $\mathbf{m}$ and $\mathbf{n}$ ) The ECM deposition was assessed by HE staining of cross-sectioned iHCEC and iFECD cultured on Corning Transwell polyester membrane cell culture inserts. The thickness of ECM was quantified by Image J software ( $n=3$ ). The experiment was performed in triplicate. ${ }^{*} P<0.01$. Scale bar $=50 \mu \mathrm{m}$. CECs, corneal endothelial cells; DAPI, 4',6-diamidino-2-phenylindole; FECD, Fuchs endothelial corneal dystrophy; HE, hematoxylin and eosin; $\mathrm{Na}^{+} / \mathrm{K}^{+}$-ATPase, sodium-potassium adenosine triphosphatase; N.S., not significant; ZO-1, zonula occludens-1.

paraformaldehyde, washed with phosphate buffered saline (PBS), and blocked with $2 \%$ bovine serum albumin. Samples were incubated with antibodies against $\mathrm{Na}^{+} / \mathrm{K}^{+}$-ATPase (1:200 diluted in PBS), ZO-1 (1:300 diluted in PBS), collagen type I (1:200 diluted in PBS), collagen type IV (1:200 diluted in PBS), collagen type $(\alpha 2)$ VIII (1:50 diluted in PBS), and fibronectin (1:200 diluted in PBS) overnight at $4{ }^{\circ} \mathrm{C}$; washed in PBS; and incubated with a 1:1000 dilution of Alexa Fluor 488-conjugated secondary antibodies for $1 \mathrm{~h}$ at room temperature. Cell nuclei were stained with DAPI; then, the slides were inspected using fluorescence microscopy (TCS SP2 AOBS; Leica Microsystems, Wetzlar, Germany).

\section{Transmission Electron Microscopy}

Transwell membrane samples were washed in $0.1 \mathrm{M}$ Sorensen phosphate buffer, processed through $0.5 \%$ uranyl acetate en bloc staining, and subsequently dehydrated using an ascending ethanol series. After transferring the specimens to propylene oxide, the samples were infiltrated and embedded in Araldite CY212 resin. Ultrathin sections were collected on uncoated 
h
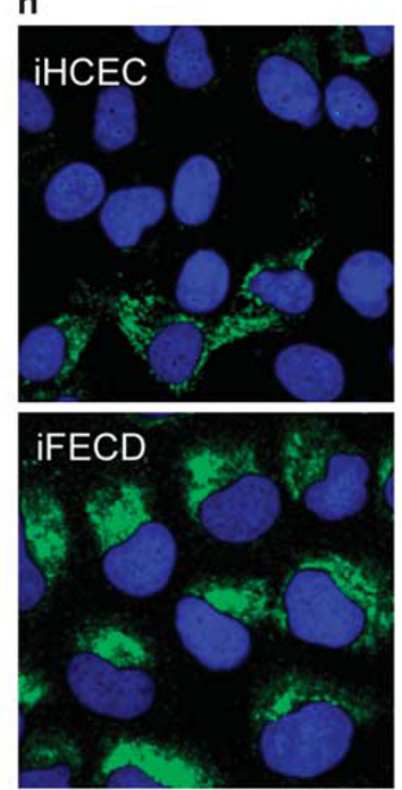

Green: collagen type I Blue: DAPI

I

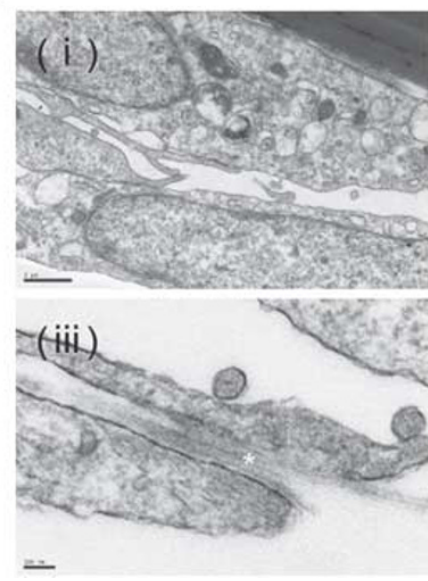

i
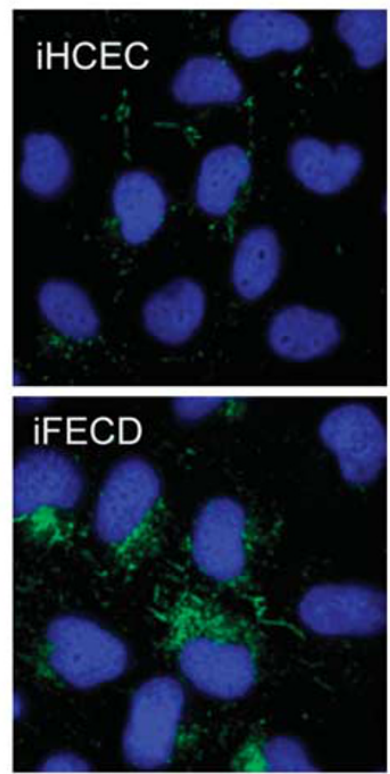

Green: fibronectin Blue: DAPI

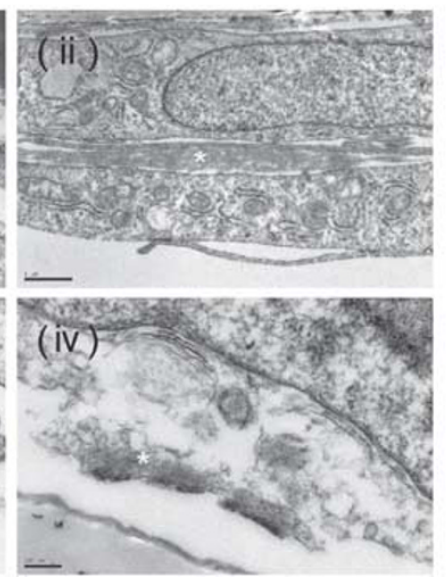

j
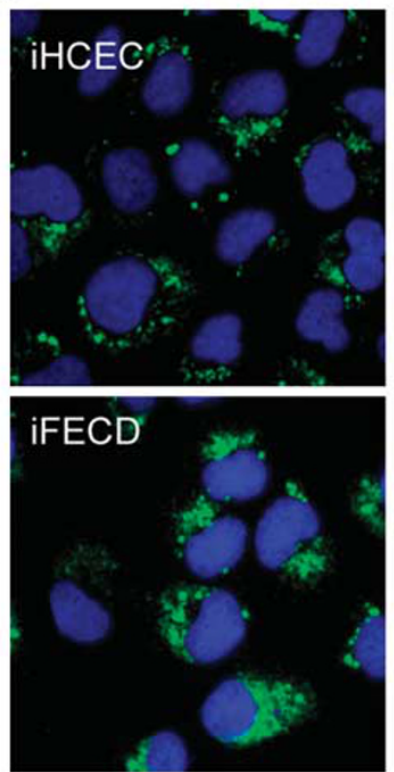

Green: collagen type IV Blue: DAPI

m

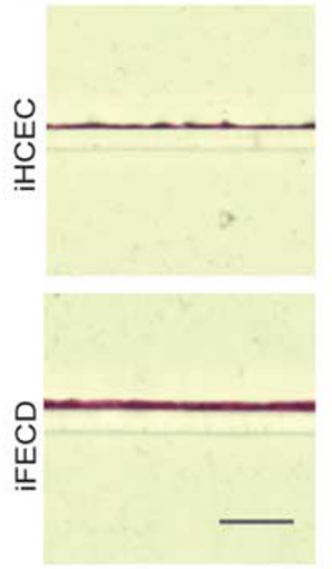

k
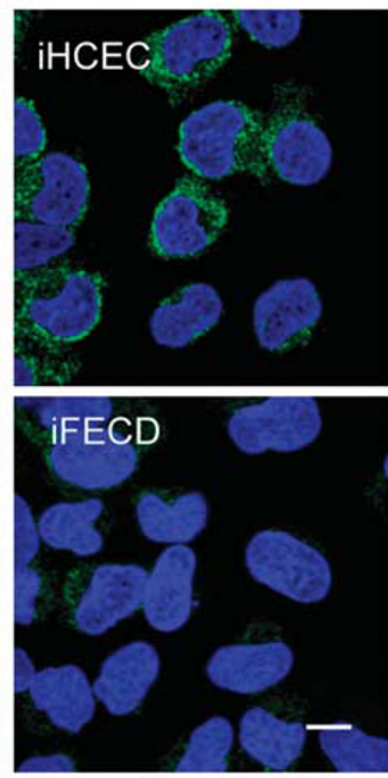

Green: collagen type VIII Blue: DAPI

n

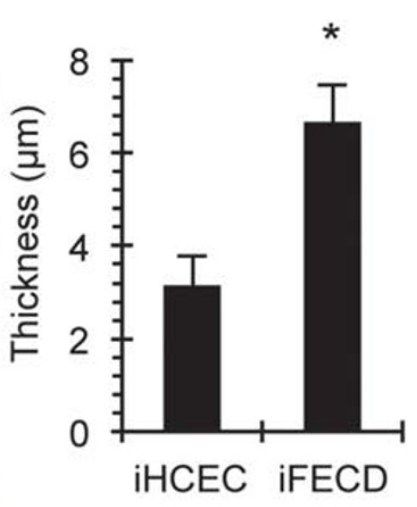

Figure 2 Continued.

G300 copper grids and stained with 1\% aqueous phosphotungstic acid and uranyl acetate. Sections were examined under a transmission electron microscope (JEOL 1010; JEOL, Tokyo, Japan) equipped with a charge-coupled device camera (Orius SC1000; Gatan, Pleasanton, CA).

\section{Quantitative Real-Time PCR}

Total RNA was extracted from the corneal endothelium of the FECD patient and donor corneas, and CDNA was synthesized by utilizing $200 \mathrm{U}$ Superscript II reverse transcriptase (Invitrogen, Karlsruhe, Germany) and random primers (Invitrogen). Quantitative real-time PCR was performed by MyIQ Thermal Cycler and software (Biorad, Munich, Germany). All samples were analyzed in duplicates with a program of $95^{\circ} \mathrm{C}$ for $10 \mathrm{~min}$ and 40 cycles of $95^{\circ} \mathrm{C}$ for $10 \mathrm{~s}$ and $60^{\circ} \mathrm{C}$ for $30 \mathrm{~s}$. For quantification, standard curves using serial dilutions $\left(10^{2}-10^{7}\right.$ copies $)$ of plasmid-cloned amplicons were run in parallel. For normalization of gene expression levels, ratios relative to glyceraldehyde-3-phosphate dehydrogenase (GAPDH) were calculated.

Gene expression levels of iHCECs and iFECDs were analyzed using TaqMan real-time PCR. Total RNA was extracted from the immortalized cells using RNeasy mini kit, and cDNA was synthesized by the use of ReverTra Ace. TaqMan primers for COL1A1, Hs00164004_ml; COL4A1, Hs00266237_ml; COL8A2, Hs00697025; FN1, Hs01549976_ml; SNAI1, Hs00195591_ml; SNAI2, Hs00950344_ml; ZEB1, Hs00232783_ml; and TaqMan pre-development human GAPDH (Applied Biosystems) were used. The PCR was performed using the StepOne (Applied Biosystems) real-time PCR system. GAPDH was used as an internal standard. 

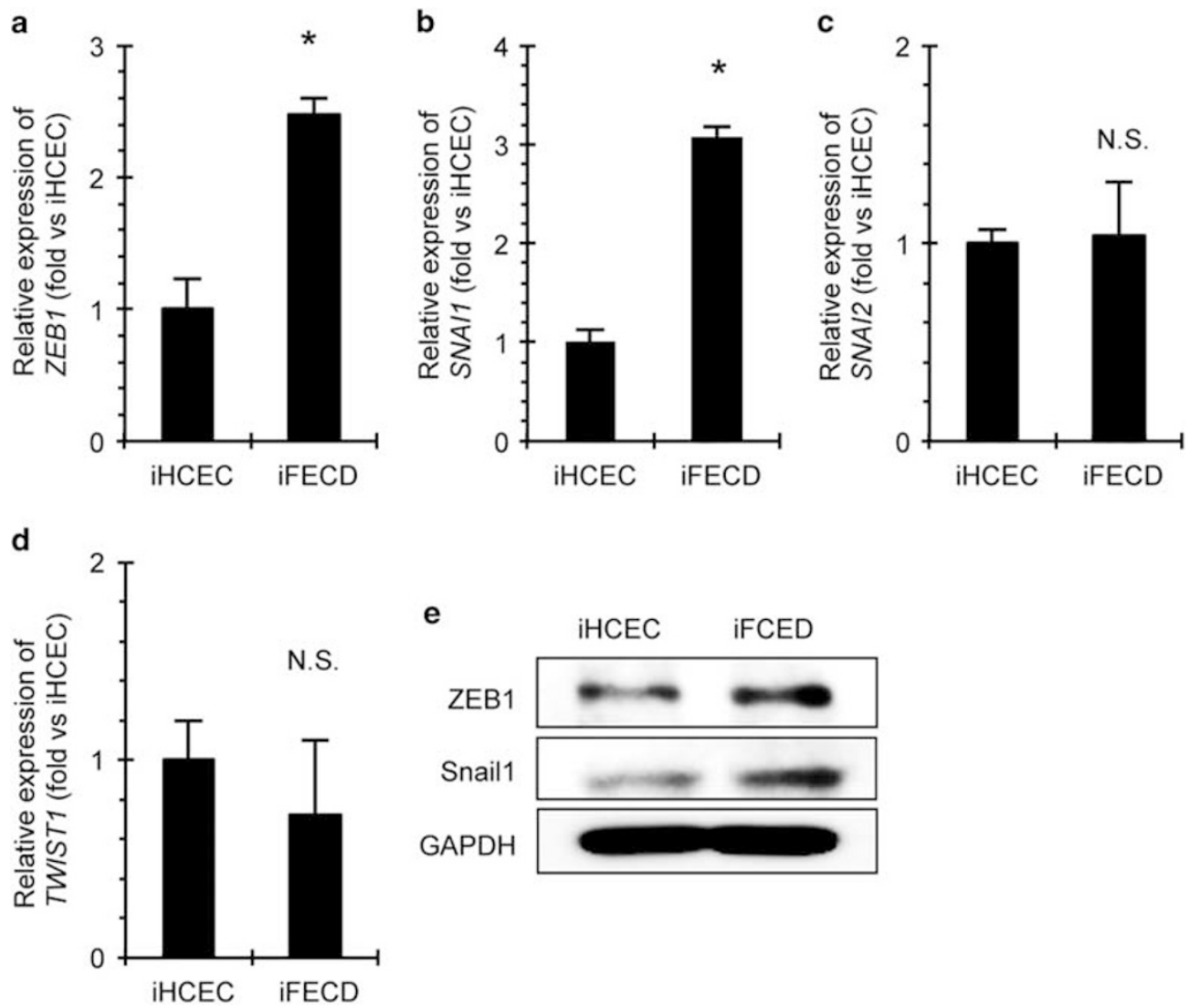

Figure 3 Expression levels of EMT-related markers in iFECD. (a-d) Expression levels of EMT-related markers (ZEB1, SNAI1, SNAI2, and TWIST1) in iHCEC and iFECD were evaluated using real-time PCR. The mean expression levels of iHCEC and iFECD established from three independent donors and patients were plotted. Triplicate experiments were performed in three independent iHCEC and iFECD. Representative data were shown both in iHCEC and iFECD batches. ${ }^{*} P<0.01$. (e) Expression levels of ZEB1 and Snail1 protein in iHCEC and iFECD were evaluated by western blotting. Experiments were performed in triplicate. EMT, epithelial mesenchymal transition; FECD, Fuchs endothelial corneal dystrophy; GAPDH, glyceraldehyde-3-phosphate dehydrogenase; N.S., not significant.

\section{Immunoblotting}

The iHCECs and iFECDs were washed with ice-cold PBS and then lysed with ice-cold RIPA buffer containing Phosphatase Inhibitor Cocktail 2 and Protease Inhibitor Cocktail. Following centrifugation at 15000 r.p.m. for $10 \mathrm{~min}$, the supernatant representing total proteins was collected. The protein concentration of the sample was assessed by use of the BCA Protein Assay Kit (Takara Bio, Otsu, Japan). The protein samples were fractionated by SDS-PAGE; proteins were transferred to PVDF membranes. The membranes were blocked with $3 \%$ non-fat dry milk for $1 \mathrm{~h}$ at RT and were incubated overnight at $4{ }^{\circ} \mathrm{C}$ with the following primary antibodies: ZEB1 (1:1000), Snail1 (1:1000), fibronectin (1:1000), and GAPDH (1:3000). After washing, the blots were incubated with horseradish peroxidase-conjugated secondary antibodies (1:5000). The blots were then developed with luminal for enhanced chemiluminescence using the ECL Advanced Western Blotting Detection Kit (GE Healthcare, Piscataway, NJ), documented using an LAS4000S (Fuji Film, Tokyo, Japan).

\section{Statistical Analysis}

The statistical significance ( $P$-value) of differences between mean values of the two-sample comparison was determined by use of the Student's $t$-test. The comparison of multiple sample sets was analyzed using Dunnett's multiple-comparison test. The values shown in the graphs represent the mean \pm s.e.m.

\section{RESULTS}

FECD Cellular Model Shows Excessive ECM Production

PAS staining showed that Descemet's membrane was thicker in FECD patients associated with excrescences 'clinically called guttae' than that in control patients (Figure 1a). Similar to previous reports, ${ }^{14,15}$ thickened Descemet's membrane expressed type I collagen and fibronection (Figures $1 \mathrm{~b}$ and $\mathrm{c}$ ). Real-time PCR demonstrated that the expression of FECDrelated ECM, COL1A1 and FN1, were significantly higher in FECD than in control (Figures 1d and e). Next, we cultured CECs derived from three FECD patients and three normal control corneas and immortalized by introduction of SV40 and hTERT genes to establish the cellular model of FECD. 

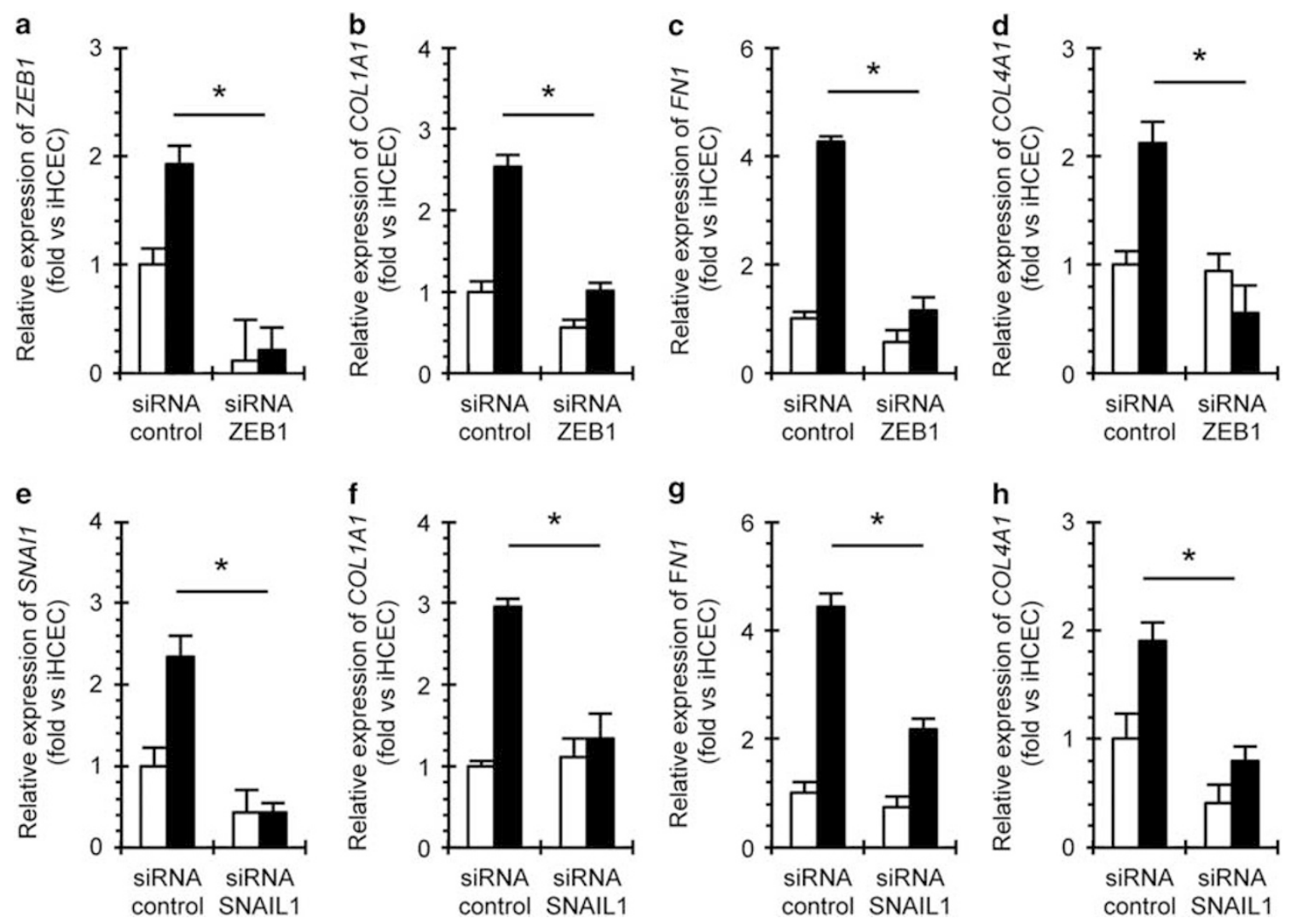

Figure 4 An upregulation of EMT-related genes was seen in iFECD cells. (a) Knockdown of ZEB1 gene by siRNA was confirmed by real-time PCR. ${ }^{*} P<0.01$. (b-d) ZEB1 gene was knocked down by siRNA, and expression levels of COL1A1, FN1, and COL4A1 were analyzed using real-time PCR. ${ }^{*} P<0.01$. (e) Knockdown of Snail1 gene by siRNA was confirmed by real-time PCR. ${ }^{*} P<0.01$. (f-h) Snail1 gene was knocked down by siRNA, and expression levels of COL1A1, FN1, and COL4A1 were analyzed using real-time PCR. ${ }^{*} P<0.01$. (i-k) ZEB1 and Snail1 was, respectively, knocked down by siRNA in iHCEC and iFECD, and production of collagen type I, fibronectin, and collagen types IV was evaluated using immunostaining. Scale bar $=100 \mu \mathrm{m}$. (I and $\mathbf{m})$ iHCEC and iFECD of which ZEB1 and Snail1 gene was knocked down by siRNA were cultured on Corning Transwell polyester membrane cell culture inserts for $48 \mathrm{~h}$. The thickness of ECM was stained by HE and was quantified by Image J software $(n=3)$. The experiment was performed in triplicate. ${ }^{*} P<0.01$. Scale bar $=50 \mu \mathrm{m}$. DAPI, 4'6-diamidino-2-phenylindole; EMT, epithelial mesenchymal transition; FECD, Fuchs endothelial corneal dystrophy; HE, hematoxylin and eosin.

Phase contrast microscopy and transmission electron microscopy (TEM) of representative iHCEC and iFECD demonstrated that both cell lines formed a regular monolayer comprising contact-inhibited hexagonal cells resembling an endothelial monolayer in vivo (Figures $2 \mathrm{a}$ and $\mathrm{b}$ ). The two cell lines were further examined for the expression of markers indicating endothelial cell function, thereby revealing characteristic staining patterns for $\mathrm{Na}^{+} / \mathrm{K}^{+}$-ATPase and ZO-1 at the plasma membranes (Figure 2c). An analysis of the expression of FECD-related ECM genes using real-time PCR demonstrated that expression levels of COL1A1 and FN1 were significant and those for COL4A1 were increased in iFECD compared with iHCEC, whereas expression levels of COL8A2 were reduced in iFECD compared with those in iHCEC (Figures $2 \mathrm{~d}-\mathrm{g}$ ). Corresponding immunofluorescence analyses showed that the protein expression of type I collagen, fibronectin, and type IV collagen was more pronounced in iFECD than in iHCEC, whereas staining of type VIII collagen was negligible in iFECD cells (Figures 2h-k), thereby confirming the mRNA expression data. Furthermore, TEM analysis showed the obvious presence of fibrillar ECM in- between cells, intracellular, and between cell and substrate in iFECD; iHCEC cells maintained normal ultra-structure morphology (Figure 21). To analyze the amount of ECM produced by iFECD and iHCEC, cells were cultured on Corning Transwell polyester membrane culture inserts until confluence. The accumulated ECM comprising types I, IV, and VIII collagen and fibronectin (Supplementary Figure S1) was visualized by HE staining and was found to be significantly broader in iFECD cultures than in iHCEC $(6.65 \pm 0.82 \mu \mathrm{m}$ and $3.14 \pm 0.64 \mu \mathrm{m}$, respectively) (Figures $2 \mathrm{~m}$ and $\mathrm{n}$ ). To analyze the potential molecular mechanisms of increased ECM production in iFECD, we investigated the expression of EMT-inducing genes-ZEB1, SNAI1, SNAI2, and TWIST1in both cell lines (Figures 3a-d). The expression of ZEB1 and SNAI1 was significantly upregulated in iFECD as compared with iHCEC, while SNAI2 and TWIST1 did not show any significant differences in expression levels. Coincidentally, western blotting demonstrated that the expression of ZEB1 and Snaill was upregulated in iFECD as compared with that in iHCEC at protein level (Figure 3e). 


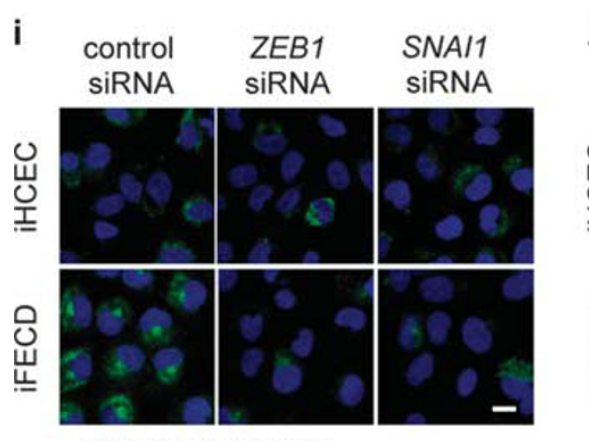

Green: Collagen type I Blue: DAPI

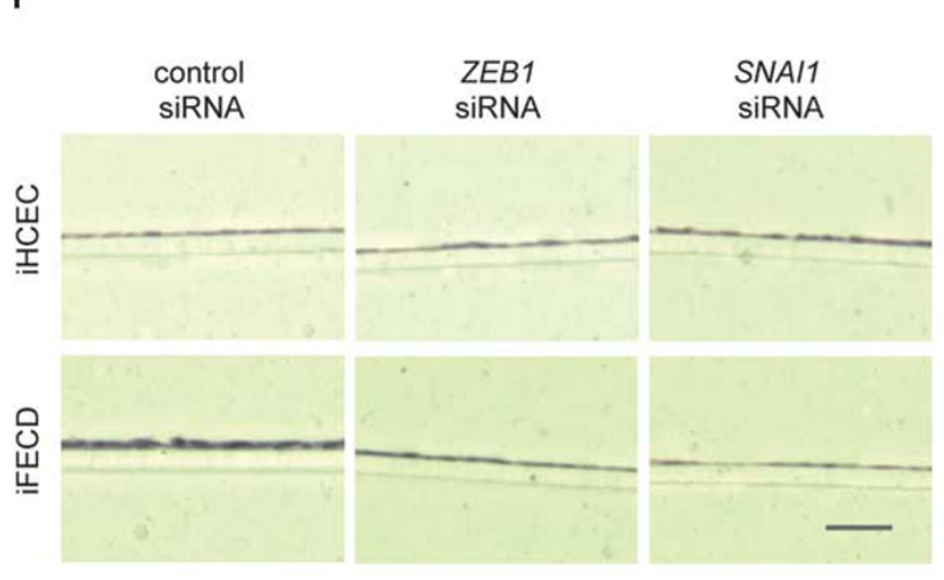

I

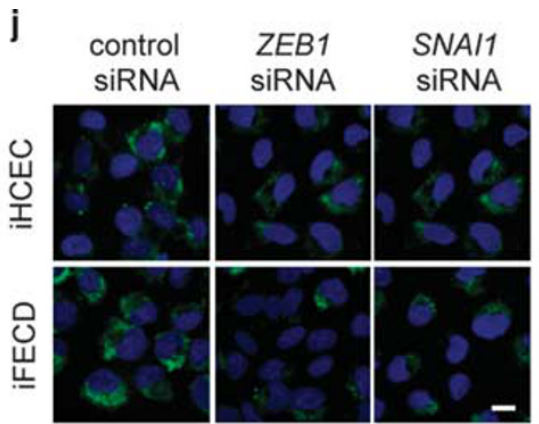

Green: Collagen type IV Blue: DAPI

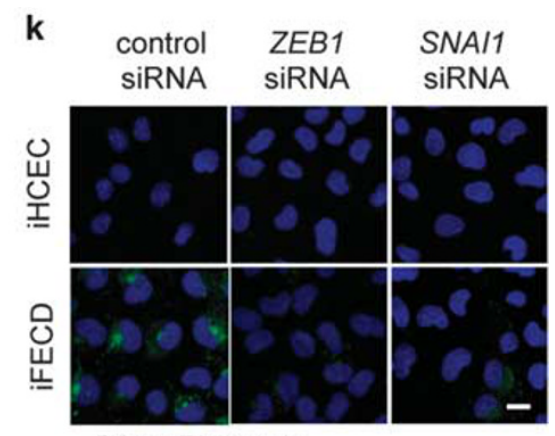

Green: Fibronectin Blue: DAPI m

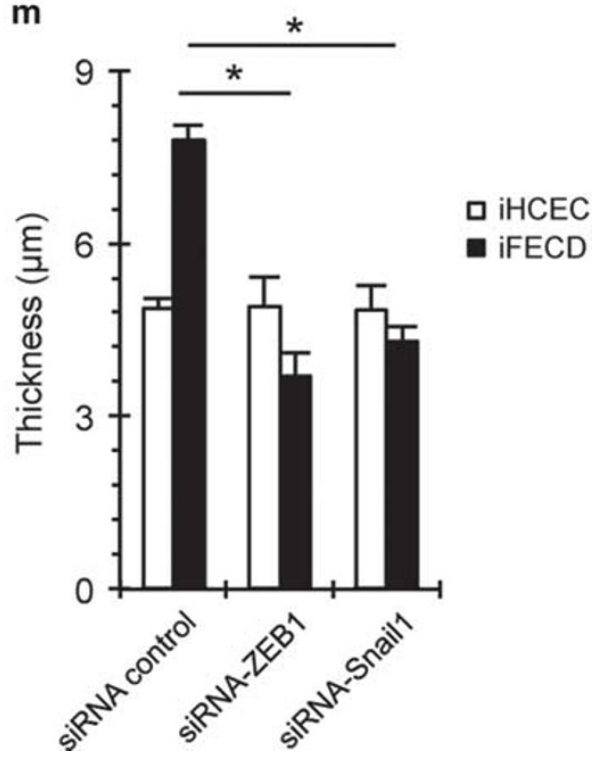

Figure 4 Continued.

\section{ZEB1 and Snail1 Regulate the Excessive Production of $E C M$ in FECD}

To further elucidate the involvement of ZEB1 and Snaill in the production of excessive ECM in FECD cells, we employed a gene knockdown strategy using siRNA. Real-time PCR analysis showed that expression levels of COL1A1, FN1, and COL4A1 were significantly decreased in iFECD, but not in iHCEC after knockdown of both ZEB1 and Snaill genes (Figures 4a-h). In accordance, immunofluorescent staining showed decreased production of type I collagen, fibronectin, and type IV collagen following downregulation of ZEB1 and Snaill only in iFECD (Figures 4i-k). Consistently, the thickness of ECM deposited by iFECD treated with ZEBI siRNA or SNAI1 siRNA was significantly lower than that treated with random siRNA $(3.70 \pm 0.4 \mu \mathrm{m}, 4.31 \pm 0.3 \mu \mathrm{m}$, and $7.79 \pm 0.3 \mu \mathrm{m}$, respectively), whereas the thickness of ECM deposited by iHCEC was unaffected (Figures 41 and $\mathrm{m}$ ). These observations suggested that both ZEB1 and Snaill played a crucial role in regulating the ECM production in FECD cells.

\section{TGF- $\beta$ Induces ECM in FECD via Upregulation of ZEB1 and Snail1}

Since TGF- $\beta$ signaling is known to be involved in the activation of EMT-related genes in various tissues, ${ }^{16}$ we assessed the effect of exogenous TGF- $\beta$ on expression of ZEB1 and Snail1 in CECs. We demonstrated that TGF- $\beta 1$ increased the expression of ZEB1 in iFECD, but not in iHCEC (Figure 5a), as well as the expression of SNAI1 both in IFECD and iHCEC in a dosedependent manner (Figure 5b). Moreover, expression levels of COL1A1, COL4A1, FN1, and COL8A2 were significantly upregulated in iFECD, but not in iHCEC by TGF- $\beta$ in a dose-dependent manner (Figures $5 \mathrm{c}-\mathrm{f}$ ). Western blotting demonstrated that TGF- $\beta$ increased the expression of ZEB1 in iFECD, but not in iHCEC. Moreover, production of fibronection was evident in iFECD by TGF- $\beta$ stimulation, but less evident in iHCEC (Figure $5 \mathrm{~g}$ ). Correspondingly, the thickness of ECM increased significantly from $6.42 \pm 0.2$ to $8.71 \pm 0.3 \mu \mathrm{m}$ in iFECD on TGF- $\beta$ stimulation, whereas it was not altered by TGF- $\beta$ in iHCEC (Figures $5 \mathrm{~h}$ and i). These observations suggest that excessive ECM production in iFECD 

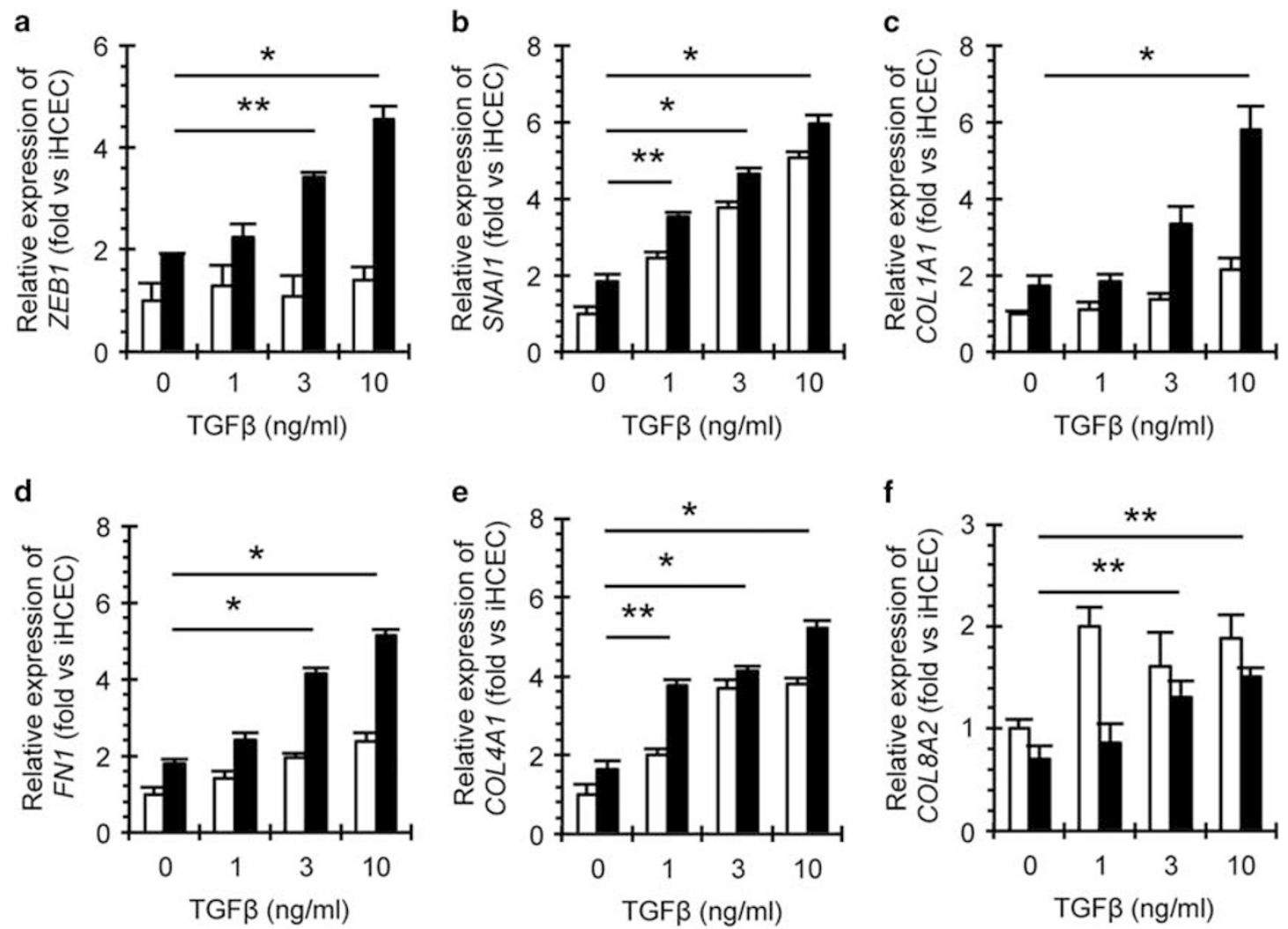

Figure 5 The effect of TGF $\beta$ on ZEB1, Snail1 expression, and on the production of ECM in iFECD. Upregulation of ZEB1 and Snail1 in iFECD cells hyper-responded against TGF $\beta$. (a-f) iHCEC and iFECD were stimulated by TGF $\beta 1(0,1,3$, and $10 \mathrm{ng} / \mathrm{ml}$ ) for $24 \mathrm{~h}$. Expression mRNA of ZEB1, SNAl1, COL1A1, FN1, and COLAA1 was evaluated by real-time PCR. The experiments were performed in duplicate in three independent batches of iHCEC and iFECD. ${ }^{*} P<0.01$. ${ }^{*} P<0.05$. (g) iHCEC and iFECD were stimulated by TGF $\beta 1(10 \mathrm{ng} / \mathrm{ml})$ for $24 \mathrm{~h}$ following $24-\mathrm{h}$ serum starvation. Expression levels of ZEB1, Snail1, and fibronectin in iHCEC and iFECD were evaluated by western blotting. Experiments were performed in triplicate. (h and i) iHCEC and iFECD were cultured on Corning Transwell polyester membrane cell culture inserts and were stimulated by TGF $\beta 1$ ( $10 \mathrm{ng} / \mathrm{ml})$ for $24 \mathrm{~h}$. The thickness of ECM was stained by HE and was quantified by Image J software $(n=3)$. The experiment was performed in triplicate. ${ }^{*} P<0.01$. Scale bar $=50 \mu$ m. ECM, extracellular matrix; FECD, Fuchs endothelial corneal dystrophy; GAPDH, glyceraldehyde-3-phosphate dehydrogenase; HE, hematoxylin and eosin.

may be the consequence of an increased responsiveness to TGF- $\beta$ stimulation as compared with iHCEC.

\section{Inhibition of TGF- $\beta$ Signaling Pathway Suppresses Excessive ECM Production via Downregulation of ZEB1 and Snail1}

The observations that the downregulation of ZEB1 and Snail1 suppressed ECM production and that TGF- $\beta$ increased expression of ZEB1 and Snaill in iFECD led us to assess the effect of inhibition of TGF- $\beta$ signaling on ECM production. Treatment of cells with SB431542, an inhibitor of TGF- $\beta$ type I ALK receptors, significantly suppressed expression levels of ZEB1 and SNAI1 in iFECD (Figures $6 \mathrm{a}$ and $\mathrm{b}$ ). Moreover, the mRNA levels of COL1A1, FN1, COL4A1, and COL8A2 were significantly reduced by SB431542 in iFECD (Figures 6c-f). Although TGF- $\beta$-stimulated ECM production was more pronounced in iFECD than in iHCEC, SB431542 decreased the expression of ECM proteins in iFECD and iHCEC to similar levels (Figures $6 \mathrm{~g}-\mathrm{j}$ ). The thickness of ECM produced by iFECD $(5.5 \pm 0.3 \mu \mathrm{m})$ was significantly increased by TGF- $\beta 2$ $(7.3 \pm 0.6 \mu \mathrm{m})$, as well as TGF- $\beta 1(9.4 \pm 0.3 \mu \mathrm{m})$ (Figures $7 \mathrm{a}$ and b). We also demonstrated that Smad3 inhibitor $(3 \mu \mathrm{M})$ and TGF- $\beta 1$-neutralizing antibody $(500 \mathrm{ng} / \mathrm{ml})$ suppressed the production of ECM to a level similar to that achieved by SB431542 in iFECD after 48-h cultivation (Figures 7a and b), thereby suggesting that inhibition of TGF- $\beta$ signaling downregulates excessive ECM production.

\section{DISCUSSION}

In the case of FECD, Descemet's membrane is thickened two to threefold. ${ }^{17}$ The thickened Descemet's membrane and excrescences comprise several ECMs such as collagen types I, IV, and VIII; fibronection; and laminin-these were considered to be secreted by affected CECs. ${ }^{14}$ Since small sample size obtained from FECD patients is an obstacle for researchers, ${ }^{11}$ we established an in vitro cellular model of FECD by immortalization of the CECs received from late-onset FECD patients. The data presented in this study identified potential overexpressed ECM proteins, which include collagen type I and fibronectin at both mRNA and protein levels and probably contribute to the excessive ECM deposition found in Descemet's membrane in FECD. 

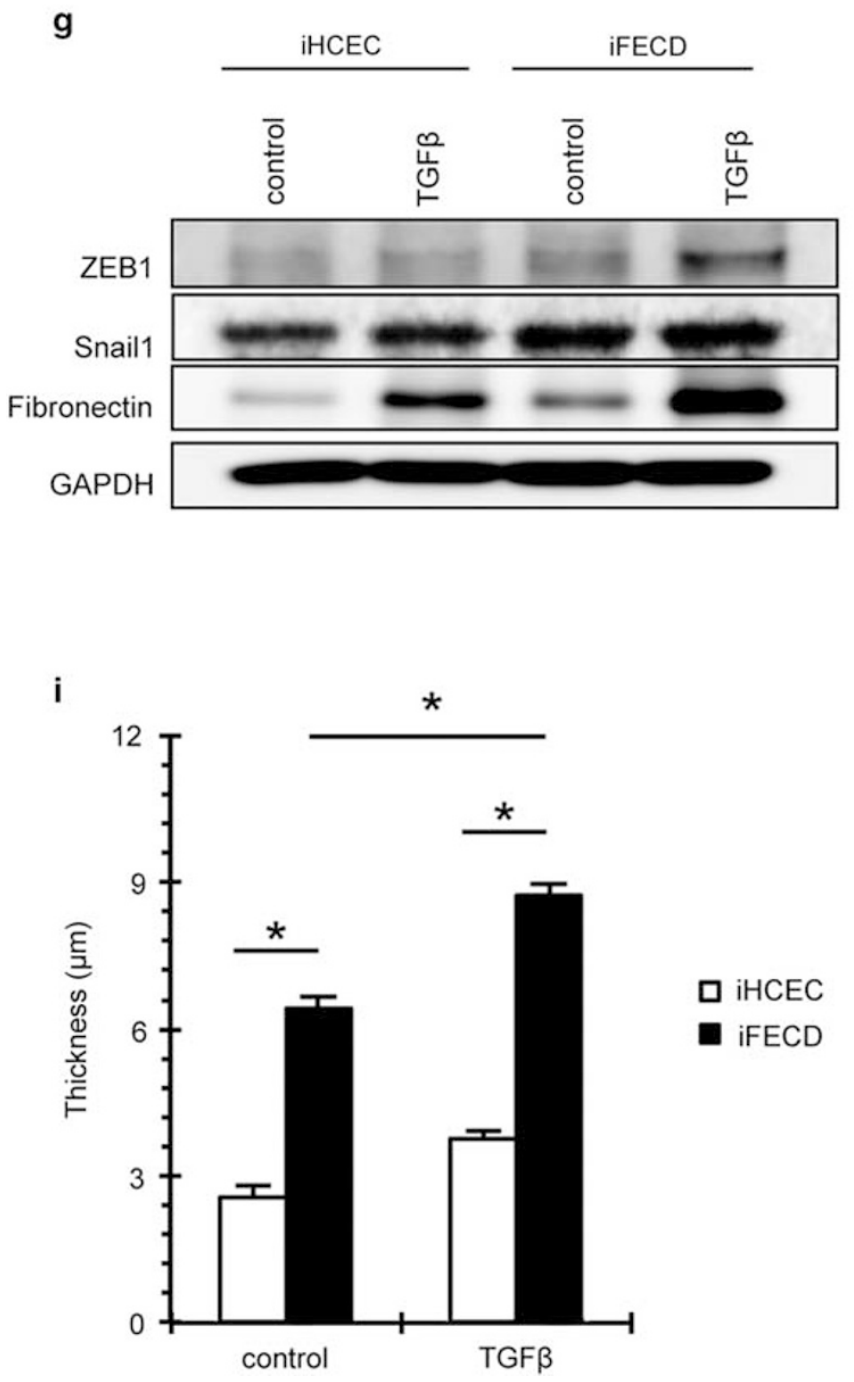

h

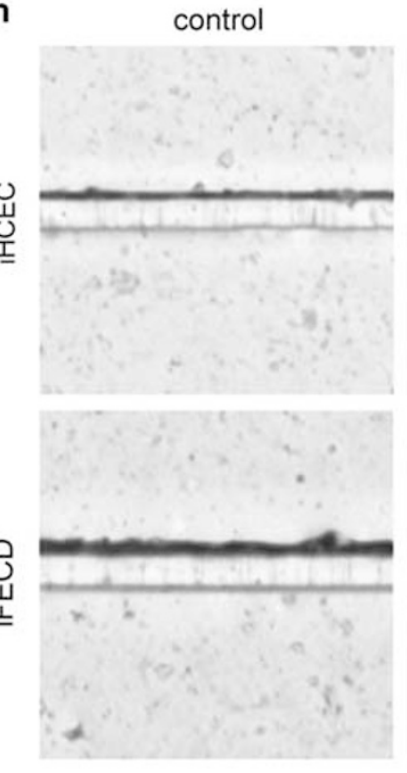

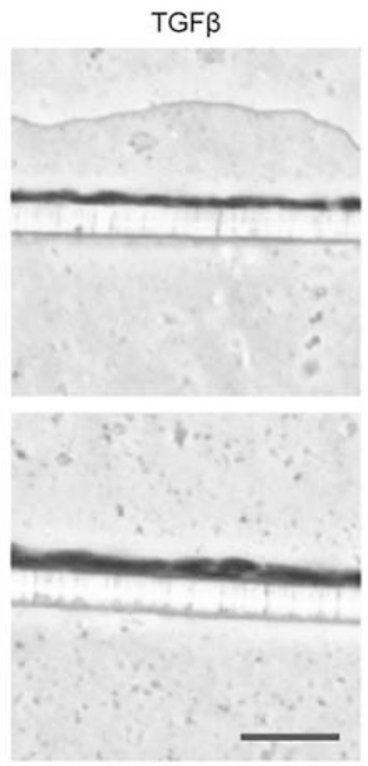

Figure 5 Continued.

However, the pathology of excessive secretion and deposition of ECM in Descemet's membrane was not clearly understood. Our current study highlights that the EMT inducer genes cause excessive ECM in FECD. EMT has an important role in appropriate embryonic development, wound healing, tissue regeneration, organ fibrosis, and cancer progression. ${ }^{18,19}$ Although the expression of EMT inducers is silenced in the adult organism, reactivation occurs when epithelial homeostasis is disturbed, such as during the fibroblastic process that occurs during organ degeneration. ${ }^{18}$ The corneal endothelium can undergo fibroblastic transformation in association with fibrotic ECM alterations in advanced stages of several disorders that involve progressive endothelial dysfunction, such as FECD, pseudoexfoliation syndrome, corneal endotheliitis, and corneal trauma; these fibroblastic changes are recognized as EMT. ${ }^{20-23}$ Here, we provide evidence that the upregulation of ECM components in FECD is caused by EMT inducers such as ZEB1 and Snail1, even though cell morphology is maintained as an endothelial phenotype without fibroblastic transformation.

Wieben et al ${ }^{24}$ demonstrated that the trinucleotide repeat expansion in TCF4 is strongly associated with late-onset FECD; $>50$ trinucleotide repeats were found in $79 \%$ of FECD and 3\% of control. Furthermore, transcription of CTG repeats resulted in nuclear foci containing condensed poly $(\mathrm{CUG})_{\mathrm{n}}$ RNA and muscleblind-like1 (MBNL1) protein, an mRNA-splicing factor. ${ }^{25,26}$ As MBNL1 is known to have a role in EMT in other types of cells, ${ }^{27,28}$ the possibility that CTG repeats in TCF4 are related to the activation of EMT inducer genes in FECD needs to be further investigated to elucidate the pathophysiology of FECD. The cellular models of FECD were established from three different patients in our current 
a

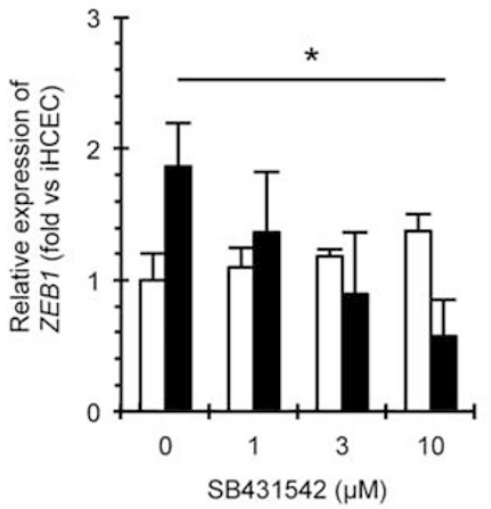

d

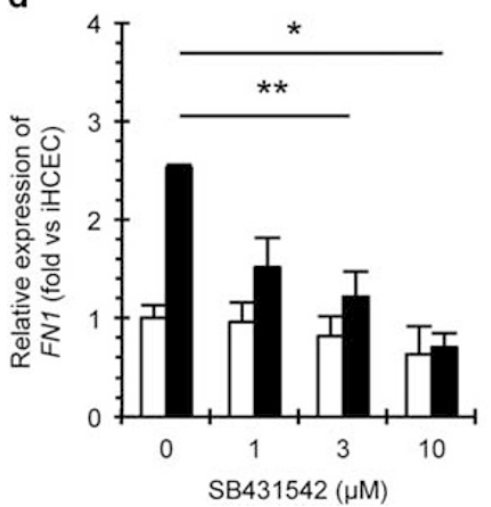

b

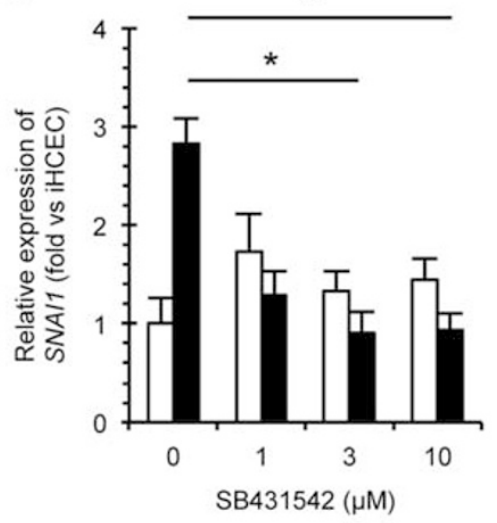

e

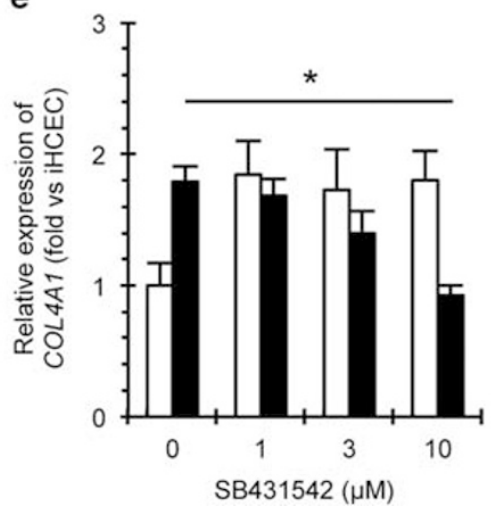

C

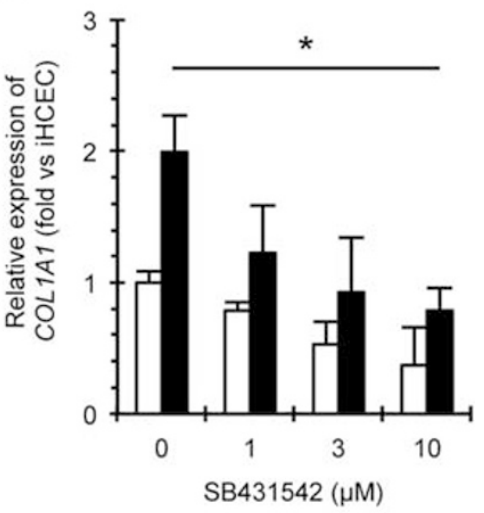

f

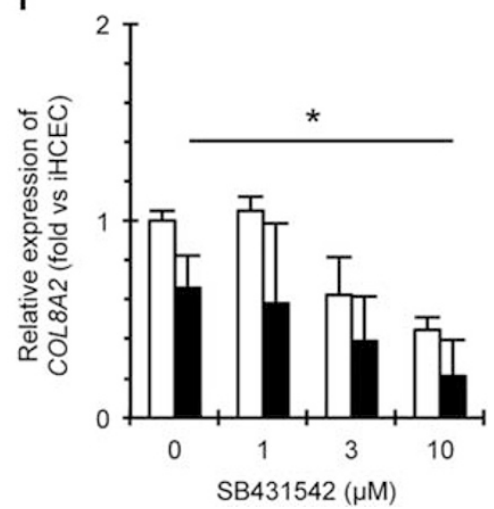

Figure 6 The effect of inhibiting TGF $\beta$ signaling pathway on suppressing ZEB1 and Snail1 gene expression, as well as on the production of ECM in iFECD. (a-f) iHCEC and iFECD were cultured with SB431542 (1, 3, and $10 \mu \mathrm{M})$ for $24 \mathrm{~h}$. Expression mRNA of ZEB1, SNAI1, COL1A1, FN1, and COL4A1 was evaluated using real-time PCR. The experiments were performed in duplicate in three independent batches of iHCEC and iFECD. ${ }^{*} P<0.01$. ${ }^{*} P<0.05$. $(\mathbf{g}-\mathbf{j})$ iHCEC and iFECD were cultured with SB431542 $(10 \mu \mathrm{M})$ for $24 \mathrm{~h}$ and production of collagen type I, fibronectin, and collagen type IV was evaluated using immunofluorescence staining. The experiments were performed in three independent batches of iHCEC and iFECD. Scale bar $=100 \mu \mathrm{m}$. DAPI, 4',6diamidino-2-phenylindole; ECM, extracellular matrix; FECD, Fuchs endothelial corneal dystrophy.

experiments, but whether patients possess CTG repeats in TCF4 was not investigated. Future experiments that establish cellular models derived from FECD patients associated with CTG repeats in TCF4 might provide a better understanding of how repeats cause the disease.

ZEB1, a zinc-finger transcription factor that binds to E2 box DNA sequence is involved in EMT through its regulation by TGF- $\beta$, FGF, and the miR200 family of microRNAs. ${ }^{16}$ The TCF4 codes for the helix-loop-helix transcription factor E2-2 that regulates cell growth and differentiation. ${ }^{29}$ Since E2-2 regulates ZEB1 expression, it is hypothesized that altering E2-2 function by TCF4 variants affects ZEB1 in late-onset FECD. ${ }^{10}$ Our study provided evidence that supports the hypothesis that ZEB1 is highly expressed in FECD and induces an EMT-like phenotype with a hallmark phenotype of FECD-secretion of excessive ECM. Interestingly, ZEB1 missense mutations were found in 7 of 384 unrelated individuals with $\mathrm{FECD}{ }^{7}$ this also suggests that ZEB1 has a role in the pathogenesis of FECD.
Snail is a common downstream target of various signaling pathways that regulate EMT. ${ }^{30}$ Although Snaill and Snaill2 in Snail family members of zinc-finger proteins (Snail1, Snail2, and Snail3) are reported to mediate EMT in various organs, ${ }^{30}$ we found that Snaill, not Snail2, is highly expressed in FECD. Snail regulates EMT phenotypes, such as increased expression of mesenchymal cell markers and decreased expression of epithelial markers. ${ }^{30}$ Although Snaill is well-recognized as an EMT inducer, an EMT-independent role is also reported. ${ }^{30} \mathrm{In}$ an EMT-independent role, Snaill acts as a potent survival factor against apoptotic stimuli through the death receptor and DNA damage. ${ }^{31,32}$ Therefore, the possibility that Snaill is induced in FECD by an apoptotic signal and acts as a pro-apoptotic factor must be further studied.

Our study highlights that the inhibition of TGF- $\beta$ signaling represses excessive ECM production by suppressing ZEB1 and Snaill expression in FECD, thereby confirming the findings of previous studies that TGF- $\beta$ induces the expression of transcription factors and transcription regulators involved in EMT in several tissues. ${ }^{33}$ Furthermore, with regard to the 

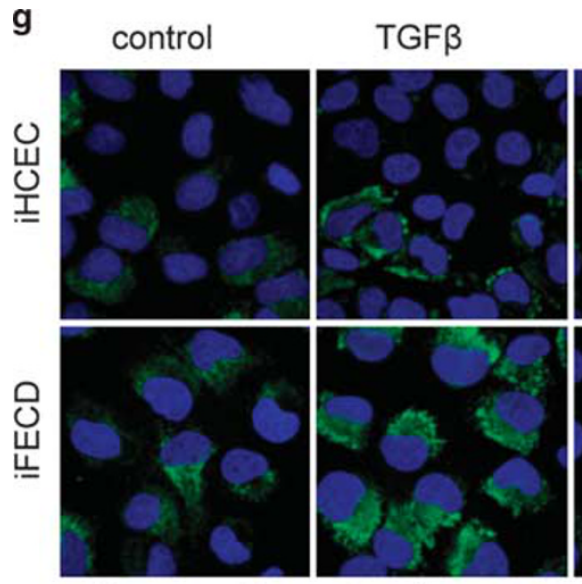

Green: collagen type I

Blue: DAPI

i control TGF $\beta$
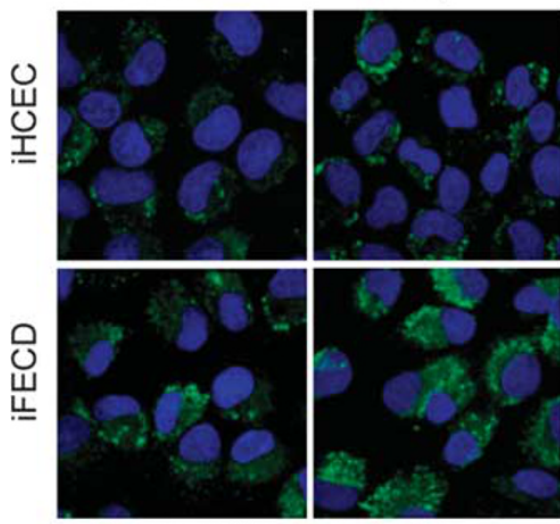

Green: collagen type IV

Blue: DAPI

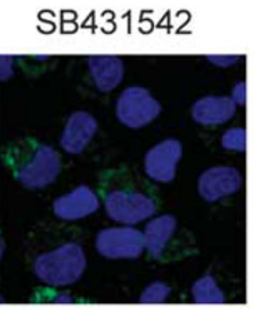

SB431542

h
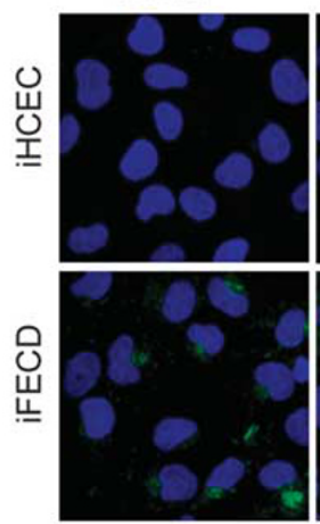

Green: Fibronectin Blue: DAPI

j
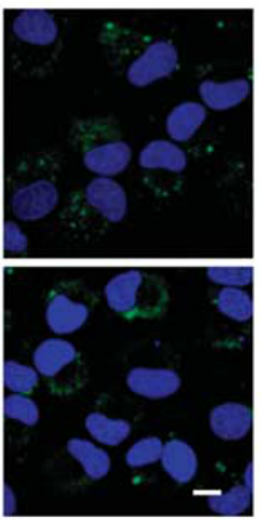

control

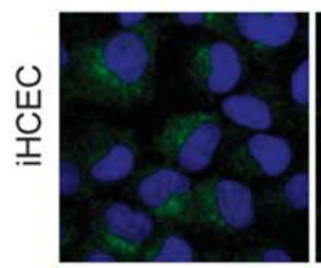

TGF $\beta$
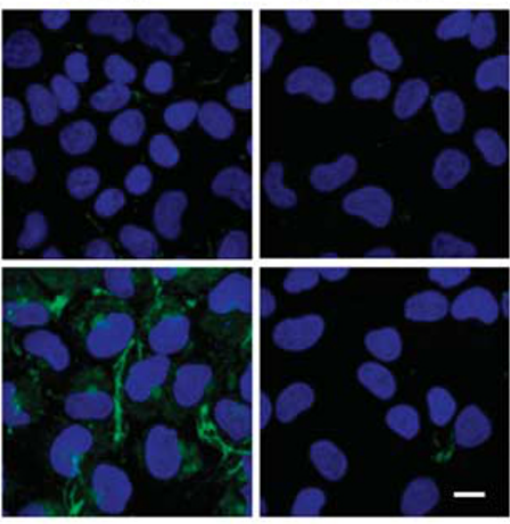

SB431542

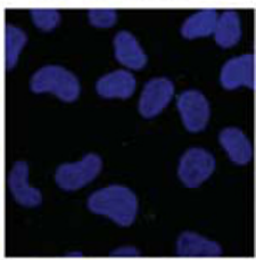

TGF $\beta$

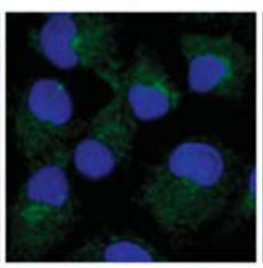

SB431542
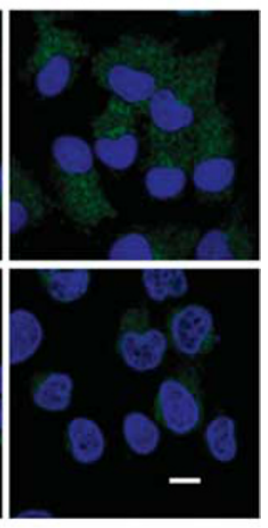

Green: collagen type VIII

Blue: DAPI

Figure 6 Continued.

corneal endothelium, we recently reported that TGF- $\beta$ triggers the secretion of fibrillar ECM proteins, such as type I collagen and fibronectin, in CECs. ${ }^{12}$ Since concentration of TGF- $\beta$ is higher in the aqueous humor than in serum, and TGF- $\beta$ is believed to be involved in the pathogenesis of FECD, as well as the homeostasis of the corneal endothelium. ${ }^{34}$ In this regard, we proposed that highly expressed ZEB1 and Snaill in FECD were responsible for the hyperresponse to TGF- $\beta$ in the aqueous humor and excessive production of ECM. Further, since abundant production of ECM proteins increase the amount of unfolded protein at endoplasmic reticulum (ER) stress, ${ }^{11}$ we speculated that excessive ECM causes not only guttae and thickening of Descemet's membrane, but also apoptosis caused by ER stress. The ER is the cellular compartment that is involved in protein folding and maturation, and many different perturbations lead to the accumulation of unfolded or misfolded proteins in the ER, thereby causing ER stress. ${ }^{35}$ Further studies that clarify whether excessive production of ECM induces ER stress and then triggers apoptosis of CECs of FECD are necessary.

To the best of our knowledge, this is the first report of EMT-related genes such as ZEB1 and Snaill as a mechanism of inducing excessive ECM proteins in late-onset FECD. Although future research is needed to elucidate whether excessive ECM proteins induce apoptosis of the corneal endothelium caused by ER stress, in this study we proposed that regulating EMT inducer genes by the suppression of the TGF- $\beta$ signaling pathway may be a feasible therapeutic tool for FECD.

Supplementary Information accompanies the paper on the Laboratory Investigation website (http://www.laboratoryinvestigation.org)

\section{ACKNOWLEDGMENTS}

We are grateful to Dr Matthias Zenkel for the valuable advice and Dr Kenta Yamasaki for providing technical assistance. This work was supported by The Funding Program for Next Generation World-Leading Researchers from the Cabinet Office in Japan (Koizumi N: LS117). 
a

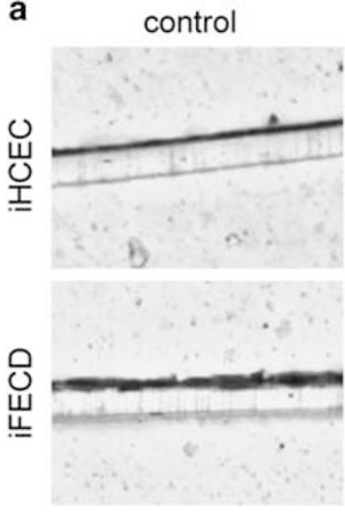

SB431542

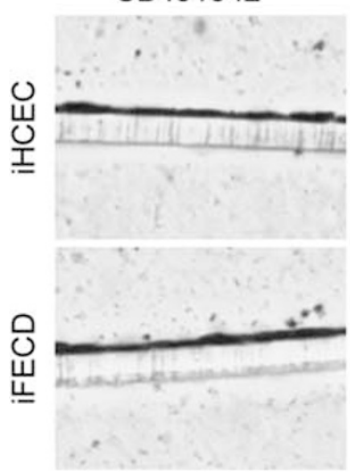

TGF $\beta 1$

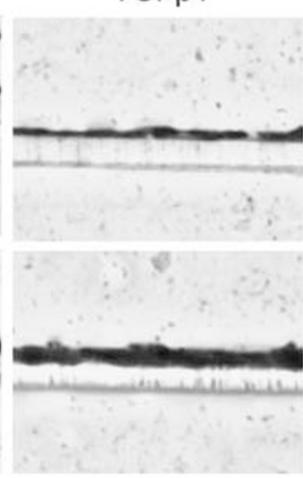

Smad 3

inhibitor

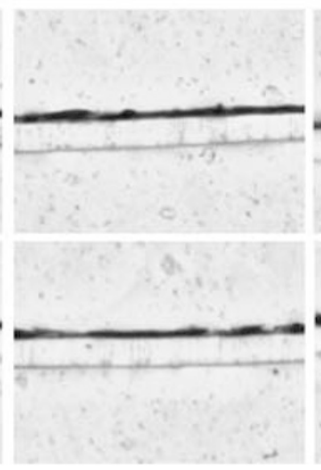

TGF $\beta 2$

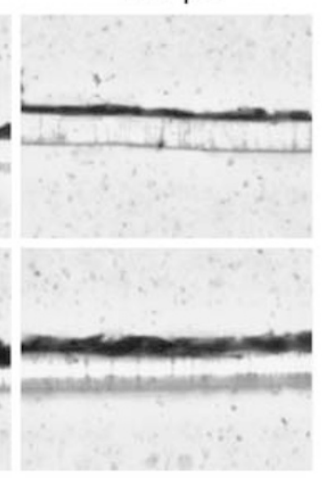

Anti-TGF $\beta 1$ antibody

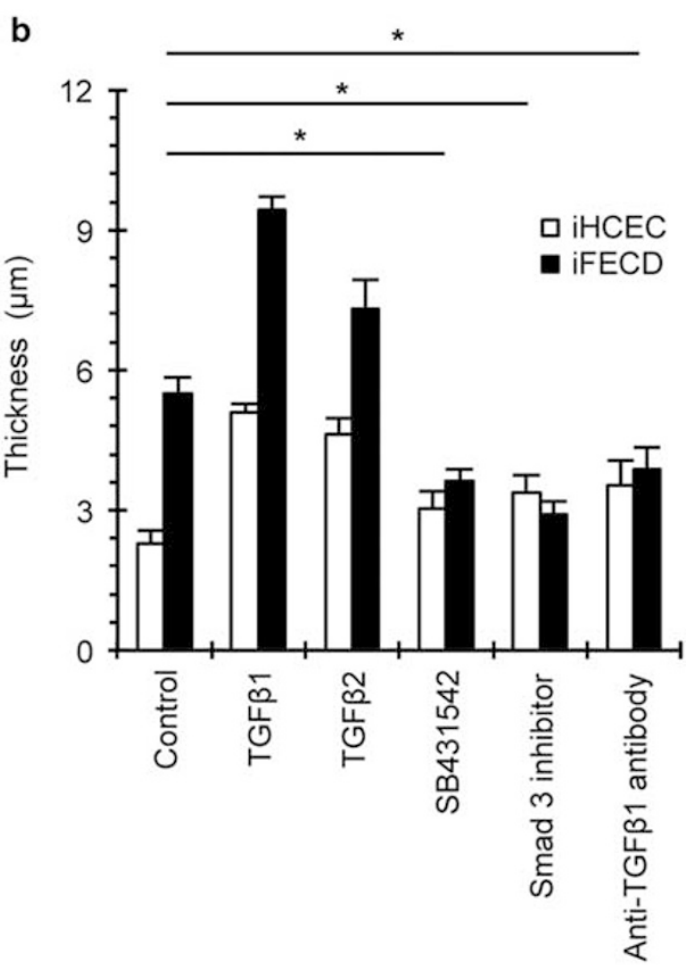

Figure 7 Effect of inhibition of the TGF $\beta$ signaling pathway on excessive production of ECM in iFECD. (a) iHCEC and ifECD were cultured on Corning Transwell polyester membrane cell culture inserts and were treated with TGF $\beta 1(10 \mathrm{ng} / \mathrm{ml}), \operatorname{TGF} \beta 2(10 \mathrm{ng} / \mathrm{ml}), \mathrm{SB} 431542(10 \mu \mathrm{M}), \mathrm{Smad} 3 \mathrm{inhibitor}(3 \mu \mathrm{M})$, or anti-TGF $\beta 1$ antibody $(500 \mathrm{ng} / \mathrm{ml})$ for $24 \mathrm{~h}$. Accumulated ECM was evaluated using HE staining. (b) The thickness of ECM was quantified by Image J software $(n=3)$. The experiment was performed in triplicate. ${ }^{*} P<0.01$. Scale bar $=50 \mu \mathrm{m}$. ECM, extracellular matrix; FECD, Fuchs endothelial corneal dystrophy; $\mathrm{HE}$, hematoxylin and eosin.

\section{DISCLOSURE/CONFLICT OF INTEREST}

NO, US-S, FEK, SK, and NK have potential financial competing interests (patents currently pending). LTYH, EPK, SK, TT, RDY and AJQ declare no conflict of interest.

1. Chi HH, Teng CC, Katzin HM. Histopathology of primary endothelialepithelial dystrophy of the cornea. Am J Ophthalmol 1958;45:518-535.

2. Kenney MC, Labermeier U, Hinds $D$ et al. Characterization of the descemet's membrane/posterior collagenous layer isolated from fuchs' endothelial dystrophy corneas. Exp Eye Res 1984;39:267-277.

3. Tan DT, Dart JK, Holland EJ et al. Corneal transplantation. Lancet 2012;379:1749-1761.

4. Lorenzetti DW, Uotila MH, Parikh $\mathrm{N}$ et al. Central cornea guttata. incidence in the general population. Am J Ophthalmol 1967;64: 1155-1158.

5. America Eye Bank Association of America. Eye Banking Statistical Report. Washington, DC, USA 2012.

6. Mehta JS, Vithana EN, Tan DT et al. Analysis of the posterior polymorphous corneal dystrophy 3 gene, Tcf8, in late-onset fuchs endothelial corneal dystrophy. Invest Ophthalmol Vis Sci 2008;49:184-188.

7. Riazuddin SA, Zaghloul NA, Al-Saif A et al. Missense mutations in Tcf8 cause late-onset fuchs corneal dystrophy and interact with $\mathrm{Fcd} 4$ on chromosome 9p. Am J Hum Genet 2010;86:45-53.

8. Vithana EN, Morgan PE, Ramprasad V et al. slc4a11 mutations in fuchs endothelial corneal dystrophy. Hum Mol Genet 2008;17:656-666.

9. Riazuddin SA, Vithana EN, Seet LF et al. Missense mutations in the sodium borate cotransporter Slc4a11 cause late-onset fuchs corneal dystrophy. Hum Mutat 2010;31:1261-1268.
10. Baratz $\mathrm{KH}$, Tosakulwong N, Ryu E et al. E2-2 protein and fuchs's corneal dystrophy. N Engl J Med 2010;363:1016-1024.

11. Engler C, Kelliher C, Spitze AR et al. Unfolded protein response in fuchs endothelial corneal dystrophy: a unifying pathogenic pathway? Am J Ophthalmol 2010;149:194-202.

12. Okumura N, Kay EP, Nakahara $M$ et al. Inhibition of Tgf-Beta signaling enables human corneal endothelial cell expansion in vitro for use in regenerative medicine. PLoS One 2013;8:e58000.

13. Okumura N, Nakano S, Kay EP et al. Involvement of cyclin D and P27 in cell proliferation mediated by rock inhibitors Y-27632 and Y-39983 during corneal endothelium wound healing. Invest Ophthalmol Vis Sci 2014;55:318-329.

14. Gottsch JD, Zhang C, Sundin $\mathrm{OH}$ et al. Fuchs corneal dystrophy: aberrant collagen distribution in an L450w mutant of the Col8a2 gene. Invest Ophthalmol Vis Sci 2005;46:4504-4511.

15. Weller JM, Zenkel M, Schlotzer-Schrehardt $U$ et al. Extracellular matrix alterations in late-onset fuchs' corneal dystrophy. Invest Ophthalmol Vis Sci 2014;55:3700-3708.

16. Miyazono K. Transforming growth factor-beta signaling in epithelialmesenchymal transition and progression of cancer. Proc Jpn Acad Ser B Phys Biol Sci 2009;85:314-323.

17. Goar EL. Dystrophy of the corneal endothelium (cornea guttata), with report of a histologic examination. Trans Am Ophthalmol Soc 1933;31:48-59.

18. Acloque $H$, Adams MS, Fishwick $K$ et al. Epithelial-mesenchymal transitions: the importance of changing cell state in development and disease. J Clin Invest 2009;119:1438-1449.

19. Kalluri R. Emt: when epithelial cells decide to become mesenchymallike cells. J Clin Invest 2009;119:1417-1419. 
20. Naumann GO, Schlotzer-Schrehardt U. Keratopathy in pseudoexfoliation syndrome as a cause of corneal endothelial decompensation: a clinicopathologic study. Ophthalmology 2000;107:1111-1124.

21. Kawaguchi R, Saika S, Wakayama $M$ et al. Extracellular matrix components in a case of retrocorneal membrane associated with syphilitic interstitial keratitis. Cornea 2001;20:100-103.

22. Koizumi N, Suzuki T, Uno T et al. Cytomegalovirus as an etiologic factor in corneal endotheliitis. Ophthalmology 2008;115:292-297.

23. Song JS, Lee JG, Kay EP. Induction of Fgf-2 synthesis by II-1beta in aqueous humor through P13-kinase and P38 in rabbit corneal endothelium. Invest Ophthalmol Vis Sci 2010;51:822-829.

24. Wieben ED, Aleff RA, Tosakulwong $\mathrm{N}$ et al. A common trinucleotide repeat expansion within the transcription factor 4 (Tcf4, E2-2) gene predicts fuchs corneal dystrophy. PLoS One 2012;7:e49083.

25. Du J, Aleff RA, Soragni E et al. RNA toxicity and missplicing in the common eye disease fuchs endothelial corneal dystrophy. J Biol Chem 2015;290:5979-5990.

26. Mootha VV, Hussain I, Cunnusamy K et al. Tcf4 triplet repeat expansion and nuclear RNA foci in Fuchs' endothelial corneal dystrophy. Invest Ophthalmol Vis Sci 2015;56:2003-2011.

27. LeMasters KE, Blech-Hermoni Y, Stillwagon SJ et al. Loss of muscleblindlike 1 promotes invasive mesenchyme formation in endocardial cushions by stimulating autocrine Tgfbeta3. BMC Dev Biol 2012;12:22.
28. Venables JP, Brosseau JP, Gadea G et al. Rbfox2 is an important regulator of mesenchymal tissue-specific splicing in both normal and cancer tissues. Mol Cell Biol 2013;33:396-405.

29. Murre C, Bain G, van Dijk MA et al. Structure and function of helix-loop-helix proteins. Biochim Biophys Acta 1994;1218: 129-135.

30. Barrallo-Gimeno A, Nieto MA. The snail genes as inducers of cell movement and survival: implications in development and cancer. Development 2005;132:3151-3161.

31. Kajita M, McClinic KN, Wade PA. Aberrant expression of the transcription factors snail and slug alters the response to genotoxic stress. Mol Cell Biol 2004;24:7559-7566.

32. Martinez-Alvarez C, Blanco MJ, Perez R et al. Snail family members and cell survival in physiological and pathological cleft palates. Dev Biol 2004;265:207-218.

33. Argast GM, Krueger JS, Thomson $\mathrm{S}$ et al. Inducible expression of Tgfbeta, Snail and Zeb1 recapitulates Emt in vitro and in vivo in a Nsclc model. Clin Exp Metastasis 2011;28:593-614.

34. Klenkler B, Sheardown H. Growth factors in the anterior segment: role in tissue maintenance, wound healing and ocular pathology. Exp Eye Res 2004;79:677-688.

35. Hetz C, Chevet E, Harding HP. Targeting the unfolded protein response in disease. Nat Rev Drug Discov 2013;12:703-719. 